\title{
Peripheral and central conduction studies in neurolathyrism
}

\author{
U K Misra, V P Sharma
}

\begin{abstract}
To study the involvement of motor and sensory pathways in neurolathyrism, 19 patients with lathyrism from Unnao, India, where lathyrism is endemic, were studied. The mean age of the patients at the time of the onset of illness was 35.8 (range 18-70) years. The mean duration of illness was 15.6 (range 2-30) years. The clinical picture comprised walking difficulty due to stiffiness and mild weakness in all 19 patients, cramps in the legs in five, frequency or urgency of micturition in five, and flexor spasms in three. There was pronounced leg spasticity with a mean Ashworth score of $4 \cdot 1$ (range 2.9-5). Central motor conduction to the tibialis anterior muscle (CMCT-TA) was slow in 14 of the 17 patients (21 sides). Slowing of peripheral motor nerve conduction, although less pronounced, was significant in the upper limb in four and the lower limb in seven sides. The tibial somatosensory evoked potentials were normal and peroneal nerve conduction was marginally impaired. Values for CMCT-TA correlated with the degree of spasticity $(p<0.02)$ whereas weakness, crossed adductor reflexes, and clonus did not. The wide variability of CMCT-TA in lathyrism may be due to involvement of different types of fibres. Large diameter fibre involvement may cause pronounced slowing. Small diameter fibre involvement could produce appreciable spasticity and mild weakness but a lesser degree of slowing or even normal conduction.
\end{abstract}

Department of Neurology, Sanjay Gandhi Post Graduate Institute of Medical Sciences, Lucknow226001 , India

U K Misra

Department of Physical Medicine and Rehabilitation, King

George's Medical College, Lucknow, India

V P Sharma

Correspondence to:

Dr U K Misra, Department of Neurology, Sanjay Gandhi Post-Graduat Institute of Medical Sciences, PB No 375 Raebareli Road, Lucknow 226001 , India.

Received 29 April 1992 and in final revised form 2 August 1993.

Accepted 9 August 1993
$(\Im$ Neurol Neurosurg Psychiatry 1994;57:572-577)

Prolonged ingestion of Lathyrus sativus causes a syndrome of pure motor spastic paraplegia known as neurolathyrism. Lathyrism is endemic in the district of Unnao, India, where $L$ sativus is still cultivated and consumed. ${ }^{1}$ Recent reports suggest an aetiological role for vegetable toxins in motor neuron disease. ${ }^{23}$ Some patients with lathyrism who have been followed up for over 40 years, have developed additional lower motor neuron signs. ${ }^{4}$

Knowledge about lathyrism is limited because of the paucity of necropsy studies. Only six studies on the pathology of lathyrism have been reported. ${ }^{5}$ The neurotoxicity of $L$ sativus has been studied in numerous experimental animals, but there has been difficulty in producing a satisfactory experimental model of human lathyrism. ${ }^{6}$ Recent studies have evaluated the effects of $L$ sativus and B'B' $^{\prime}$ aminodipropionitrile in monkeys, and found some similarity with human lathyrism. ${ }^{78}$ There are very few studies in which the neurophysiological changes in lathyrism have been investigated. ${ }^{910}$ We studied conduction in peripheral nerves and central pathways and the correlations of these with the clinical signs of lathyrism.

Patients and methods

CLINICAL EVALUATION

Nineteen patients with lathyrism from the villages of Unnao, India, volunteered for electrophysiological study. The diagnosis of lathyrism was based on the criteria of Prasad and Sharan, which include (a) occurrence of a number of cases endemically in geographic areas where lathyrism is known; (b) history of intake of seeds of $L$ sativus; (c) Progressively chronic course of the disorder; (d) purity of pyramidal tract involvement; (e) absence of sensory disorder and minimal or complete absence of sphincter involvement. ${ }^{11}$ A detailed medical history and a physical examination including neurological examination was performed. The power of hip flexors, extensors, adductors and abductors; knee flexors and extensors; ankle dorsiflexors and plantarflexors of either side were graded on the MRC scale and the unweighted average of these scores was taken as the inferior extremity power score (IEPS). Spasticity was evaluated by the Ashworth score, which is the sum of the score for hip (flexion and abduction), knee, and ankle joints on both sides divided by 8 . The tone on each joint was assessed on a five point scale that comprised: (1) No increase in tone; (2) slight increase in tone giving a catch when the affected part was moved; (3) more pronounced increase in tone but the affected part was easily flexed; (4) considerable increase in tone, passive movement was difficult; (5) affected part was rigid in flexion or extension. Flexor spasms were also graded. ${ }^{12}$

\section{NEUROPHYSIOLOGICAL STUDIES}

The neurophysiological tests included motor and sensory nerve conduction velocity, somatosensory evoked potentials, and transcranial cortical and spinal stimulation studies. The normal values for the electrophysiological variables were obtained from 32 healthy hospital employees who were matched for age, sex, and socioeconomic state. 
Motor nerve conduction velocity of the ulnar nerve in the elbow to wrist segment and a peroneal motor conduction study of the knee to ankle segment was also carried out. Sensory conduction in the sural nerve was measured by antidromic stimulation distal to the lower border of the venter musculi gastrocnemius, $14-16 \mathrm{~cm}$ above the lateral malleolus. The recording surface electrode was placed between the Achilles tendon and the lateral malleolus. ${ }^{13}$

Bilateral tibial somatosensory evoked potentials (SEPs) were obtained by stimulation of the posterior tibial nerves below the medial malleolus at $1 \mathrm{~Hz}$, sufficient to produce a painless visible contraction of the big toe. The recording by surface electrode was done from spinous process of $\mathrm{Ll}$ and $\mathrm{Cz}^{\prime}$ (2 $\mathrm{cm}$ caudal to $\mathrm{Cz}$ ) with reference electrodes at $\mathrm{L} 3$ and $\mathrm{Fz}$ respectively. The latencies of spinal SEPs were measured at the peak of the initial negative deflection and those of cortical SEPs at first peak of the positive polarity. Latencies of N21, P40, N50, and P60 waves and peak to peak amplitudes were measured. N21-P40 central sensory conduction time (CSCT) was also calculated. ${ }^{14}$

To stimulate the motor cortex and cervical and lumbar spine a Digitimer D 180 stimulator delivering a single electrode shock up to 750 $V$ with a time constant of 50-100 $\mu$ s was used. Stimulating electrodes were $1 \mathrm{~cm}$ diameter saline soaked felt pads mounted on a plastic handle. To activate the abductor digiti minimi the cathode was placed at the vertex and the anode $7 \mathrm{~cm}$ laterally and $1 \mathrm{~cm}$ anterior to a line from vertex to tragus $\left(\mathrm{C}^{\prime}\right.$ or $\left.\mathrm{C}^{\prime}\right)$. For activating the tibialis anterior the anode was kept on the vertex $(\mathrm{Cz})$ and the cathode was $7 \mathrm{~cm}$ posterior to it. For cervical and lumbar stimulation the cathode was placed below the spinous process of $\mathrm{C} 7$ and $\mathrm{T} 12$ respectively with the anode proximal to the cathode. Motor evoked potentials (MEPs) were recorded by surface electrodes placed on the abductor digiti minimi or tibialis anterior. To obtain the maximum cortical response the subject was asked to tense the abductor digiti minimi or tibialis anterior slightly $(10 \%)$ in respective recordings. On getting the maximum response three responses were obtained at a $10 \mathrm{~s}$ interval. The EMG signals were amplified and filtered through $20 \mathrm{~Hz}-2 \mathrm{kHz}$ at a gain of $0.5-2 \mathrm{mV} /$ division. Stimulus intensity was between $90 \%$ and $100 \%$ of maximum output for cortical stimulation and $50 \%-60 \%$ for spinal stimulation. MEPs evoked by cervical or lumbar stimulation were recorded while the subject was relaxed. Minimal onset latency and amplitude of the negative phase of the MEP were recorded. Central motor conduction time (CMCT) was calculated for the upper limb (CMCT-ADM) by subtracting the latency of MEP on C7 stimulation from that on cortical stimulation $\left(\mathrm{C}^{\prime}\right.$ or $\left.\mathrm{C}^{\prime}\right)$. Central motor conduction time for the segment innervating tibialis anterior (CMCT-TA) was calculated by subtracting the latency of MEP on lumbar stimulation from that on $\mathrm{Cz}$ stimulation. ${ }^{15}$ To exclude the effect of height on the latency or conduction time of the evoked potentials they were standardised by dividing the product of individual latency and the average height of the groups $(163 \mathrm{~cm})$ by the height of the patient. The laboratory temperature ranged between $21^{\circ}$ (and $23^{\circ} \mathrm{C}$ ).

The difference of the mean of electrophysiological variables between patients with lathyrism and controls was evaluated by Student's $t$ test. The cut off point for the abnormality of neurophysiological variables was taken as the mean $\pm 2 \mathrm{SD}$. The relation between duration of illness was evaluated by linear correlation coefficient $(r)$. The dependence of CMCTTA on some of the qualitative variables such as power score, use of stick, Ashworth score, presence of cross adductor reflex, and ankle clonus was tested by $\chi^{2}$ test.

\section{Results}

The patients had eaten $L$ sativus since their childhood at both major meals in the form of bread and gruel(dal). The age of the patients at the time of the onset of the disease was 35.8 (range 18-70) years and their mean height was $162 \cdot 4$ (range 153-171) $\mathrm{cm}$. After developing weakness eight patients stopped eating $L$ sativus but others continued to take it, although less often and in smaller amounts. Five patients ate non-vegetarian food and six drank alcohol occasionally. The control group's mean age was 28.9 (range 18-50) years and the mean height was 163.8 (range $147-179) \mathrm{cm}$. None of them had a history of eating $L$ sativus.

All our patients were men. The mean duration of illness was 15.6 (range 2-30) years. All of them had walking difficulty due to weakness and stiffness, cramps in the legs, and frequency or urgency of micturition were reported by five patients each. Three patients experienced flexor spasms mainly at night and one had tingling and numbness in hand and feet. The symptoms remained constant in all the patients except six who had a variable degree of improvement during the early period of illness. The improvement started after a mean duration of one month (range $0 \cdot 3-4$ ) and continued for $2 \cdot 3$ (range $0 \cdot 8-4$ ) months. The patients had a characteristic posture comprising of flexion and adduction of the hip, extension of the knees, plantar flexion of the ankles and secondary flexion of the spine (fig 1) and they walked with a characteristic spastic or scissoring gait. Most patients could walk unaided, but five needed one and one needed two sticks for walking. The leg weakness was mild to moderate; inferior extremity power score was $4 \cdot 1$ (range $2 \cdot 9-5$ ) but spasticity was the most striking feature. The mean Ashworth score was $4 \cdot 1$ (range $2 \cdot 2-5)$. Upper limbs were normal in all except two who had hyper-reflexia (patient No 6) and increased tone and hyper-reflexia (patient No 11). The sensations of pain, touch, joint position, and vibration were normal although one patient complained of tingling and numbness (patient No 6). The physical signs were 
Figure 1 Patients with lathyrism.

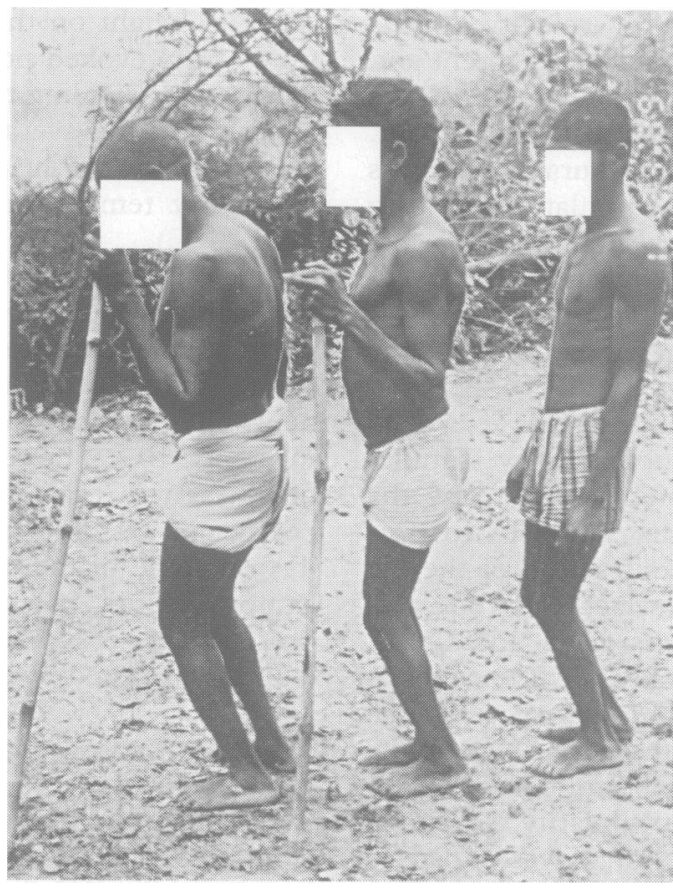

symmetrical in most patients but some degree of asymmetry was found in seven, which included asymmetry of muscle weakness (five) asymmetry of spasticity, unilateral ankle clonus, and unilateral extensor plantar response (one each).

\section{NEUROPHYSIOLOGICAL STUDIES}

On transcranial electrical stimulation MEP was recorded from the abductor digiti minimi (ADM) in all 19 patients (38 sides) and from the tibialis anterior (TA) in all 17 patients (33 sides) who were subjected to these studies. The most significant change was slowing of CMCT-TA in 14 patients (21 sides), the degree of slowing was mild to moderate in all but two patients (three sides) in whom it exceeded twice the mean value of normal controls. There was also significant slowing of peripheral conduction on spinal stimulation in the patients as a group when compared with the control population although individual latency values were prolonged in only five patients (seven sides). The amplitude of MEP on cortical stimulation showed pronounced variation even in controls; although there was a significant group difference but the individual values were normal. In upper limb recording, the MEP latency on cortical stimulation was prolonged in eight patients (12 sides) and that on C7 stimulation in three patients (four sides) although CMCT-ADM was normal in all except one patient, indicating predominant peripheral slowing in these patients. Tibial SEPs were recorded in 16 patients (32 sides). The latency, amplitude, and the configuration of different waves and CSCT were normal in all the patients and the group difference was also non-significant. Nerve conduction studies performed on 16 patients revealed slowing of peroneal motor conduction velocity in six and sural sensory conduction velocity in one patient. The amplitude of peroneal compound muscle action potential, sural nerve potential, and the amplitude of MEP on cervical and lumbar spine stimulation were normal. Concentric needle EMG of the vastus medialis, tibialis anterior, gastrocnemius, and extensor digitorum brevis did not reveal any spontaneous activity; the motor unit potentials were of normal duration and shape but their recruitment was reduced. This may have been due to spasticity. The clinical and electrophysiological features of a patient with lathyrism are presented in the following case report.

\section{CASE REPORT}

A 50 year old man whose height was $164 \mathrm{~cm}$ developed acute onset of leg weakness. He felt as if his legs were buried in mud. The weakness progressed for one week and he was unable to get out of bed. In next three to four months there was gradual improvement with a stationary course thereafter. He had consumed $L$ sativus in both major meals since his childhood but had eaten it rarely for the past seven years. He was not addicted to any intoxicant and his medical history was not relevant. The patient was of average build and nutrition. $\mathrm{He}$ had pronounced leg spasticity (Ashworth score 5) and walked with the help of two crutches. The right inferior extremity was slightly weaker than the left (IEPS 3.9). Knee and ankle reflexes were exaggerated,

Tibialis anterior recording
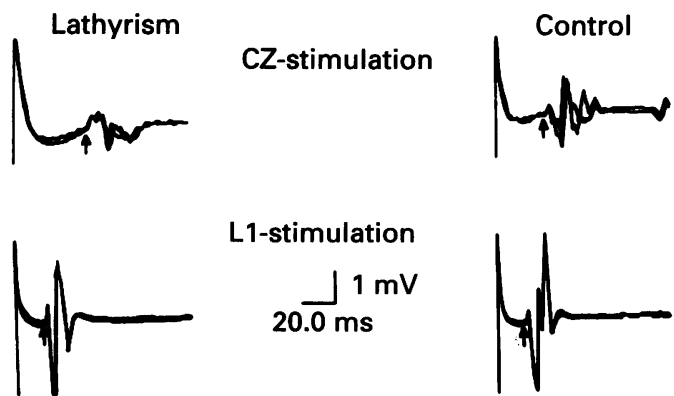

L1-stimulation $20.0 \mathrm{~ms}$

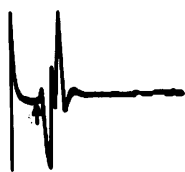

Figure 2 Transcranial electrical stimulation studies showing prolongation of CMCT-TA in a patient with lathyrism (height $153 \mathrm{~cm}$ ), CMCT-TA in the patient is $25.6 \mathrm{~ms}$ and that in the control (height $147.5 \mathrm{~cm}$ ) $12 \cdot 4 \mathrm{~ms}$. Arrow $(\uparrow)$ indicates the onset latency of MEP.

$\star=p<0.05 ;{ }^{\star \star}=p<0.01$. MEP $=$ motor evoked potential; CMCT $=$ central motor conduc tion time; CMAP = compound muscle action potential; SNAP = sensory nerve action potential. 
ankle clonus was present, the plantar responses were extensor bilaterally, and there were occasional flexor spasms in the lower limbs. His sensations and bladder functions were normal. His haemoglobin concentration, urinalysis, erythrocyte sedimentation rate, and blood sugar, blood urea, serum creatinine, and serum protein concentrations were normal. Radiographs of the cervical and thoracolumbar spine in anteroposterior and lateral views were normal and a CT scan of the spinal cord from the sixth thoracic to first lumbar spine with $2 \mathrm{~mm}$ cuts was also normal.

Motor evoked potential latency (amplitude) of the right and left tibialis anterior on $\mathrm{Cz}$ stimulation was $35.6 \mathrm{~ms}(1.7 \mathrm{mV})$ and 34.0 $\mathrm{ms}(1.7 \mathrm{mV})$; on lumbar stimulation $17.6 \mathrm{~ms}$ $(1.2 \mathrm{mV})$ and $17.6 \mathrm{~ms}(1.1 \mathrm{mV})$, CMCT-TA was $18.0 \mathrm{~ms}$ and $16.4 \mathrm{~ms}$ respectively. CMCT-ADM on the right side was $5.2 \mathrm{~ms}$ and on the left side $5.0 \mathrm{~ms}$. Tibial SEPs were normal bilaterally and CSCT on the right side was $18.1 \mathrm{~ms}$ and on the left side $19.0 \mathrm{~ms}$. Motor conduction velocity of the peroneal nerve was $48.3 \mathrm{~m} / \mathrm{s}$, sensory conduction velocity of the sural nerve was $50 \mathrm{~m} / \mathrm{s}$, and the amplitude of the sural nerve potential was $7 \cdot 1 \mu \mathrm{V}$. An EMG of inferior extremity muscles revealed a reduced interference pattern. This highlights the presence of severe leg spasticity with mild weakness and moderate motor conduction to the legs in lathyrism.

\section{CLINICAL AND NEUROPHYSIOLOGICAL CORRELATION}

Of the various clinical variables evaluated, the degree of spasticity significantly correlated with CMCT-TA $\left(\chi^{2}=5.77, \mathrm{p}<0.02\right)$, but the presence of clonus $\left(\chi^{2}=2 \cdot 02, N S\right)$, dependence on walking stick $\left(\chi^{2}=0 \cdot 80, \mathrm{NS}\right)$, cross adductor reflex $\left(\chi^{2}=0.90, \mathrm{NS}\right)$, and inferior extremity power score $\left(\chi^{2}=0.01, \mathrm{NS}\right)$ did not. The clinical signs were symmetrical in most patients but some degree of asymmetry was present in seven. CMCT-TA revealed significant right to left asymmetry (more than $3.7 \mathrm{~ms}$ ) in five patients, which correlated with asymmetry of clinical signs in three. On clinical examination definite evidence of peripheral neuropathy was not present in any patient, although the slowing of peroneal motor conduction velocity and MEP latency on $\mathrm{C7}$ and L1 stimulation did suggest the involvement of peripheral motor pathways. Normal sural sensory conduction and tibial SEP confirmed normal sensations in lathyrism.

\section{Discussion}

The electrophysiological evaluation of patients with lathyrism has revealed the most significant changes in the descending motor pathways to the inferior extremities. Central motor conduction time is a measure of the conduction in the fastest conducting motor pathways. ${ }^{16}$ On transcranial electrical stimulation the contralateral EMG responses are mediated by the large diameter corticospinal tract. ${ }^{17}$ The role of small pyramidal fibres, which account for $90 \%$ of corticospinal tracts, ${ }^{18}$ are not evaluated by this technique. Values for CMCT-TA in patients with lathyrism have ranged from normal in 12 sides, to pronounced slowing in three sides but a mild to moderate degree of prolongation was the most frequent abnormality; this was present in 18 sides. In lathyrism the most striking clinical feature is considerable spasticity with relatively mild weakness. Pronounced prolongation of CMCT-TA may be due to the involvement of large diameter and fast conducting motor pathways, whereas the involvement of smaller diameter fibres may result in a lesser degree of slowing or even normal CMCT. Normal CMCT-TA in the presence of spasticity as in patients Nos 6, 8, and 13 could be due to the involvement of small diameter corticospinal fibres, which may result in spasticity without producing significant weakness or slowing of central motor conduction. Of the clinical signs, only the degree of spasticity was significantly related to CMCT-TA $(p<0.02)$, whereas weakness, use of a walking stick, cross adductor reflex, and clonus were not. Lack of correlation or poor correlation between CMCT and hyperreflexia, spasticity, and the conventional tests of motor power have also been reported in multiple sclerosis. ${ }^{19-21}$ The clinical assessment of strength relies on tonic muscle activation. Tonic and phasic muscle activity may use different descending motor inputs, ${ }^{22}$ which may obscure the correlation.

Latency of MEP in upper and lower limbs was prolonged but central motor conduction was mainly affected in the motor fibres to the leg muscles. This suggests specific affinity of these fibres for lathyrus toxin. Moreover, the largest diameter corticospinal fibres reach to the lumbar and sacral region, ${ }^{23}$ which could also explain the pronounced prolongation of CMCT-TA. Our results are consistent with the involvement of the thoracolumbar region of the spinal cord as reported in some necropsy studies. ${ }^{24} 25$ Our results differ from that of Hugon et al, in which tibialis anterior responses were not recordable after magnetic stimulation in some patients. ${ }^{10}$

Changes in central motor conduction in lathyrism can be better interpreted by comparing them with certain more clearly understood disorders. Multiple sclerosis results in pronounced slowing of central motor conduction in the upper limbs, exceeding three times the normal in $10 \%$ and twice the normal in one third. ${ }^{19}$ In lathyrism the slowing of CMCTTA was comparable with multiple sclerosis in two patients, but in most the slowing was mild to moderate. By contrast with multiple sclerosis, CMCT-ADM was normal in lathyrism. Peripheral axonal and neuronal degeneration that occur in motor neuron disease and stroke result in reduction of the amplitude of MEP. ${ }^{16}$ ${ }^{26} 27$ The low amplitude of MEP recorded from the tibialis anterior on cortical stimulation, however, revealed significant group differences but the individual values were normal. Subtle changes in amplitude should be carefully interpreted because of the pronounced 
variability of MEP amplitude. Despite a long duration of lathyrism there was no clinical evidence of peripheral nerve involvement in our patients although additional lower motor neuron signs have been reported in long standing cases of lathyrism from Israel and Bangladesh. ${ }^{510}$ Hereditary spastic paraplegia resembles lathyrism in having predominant lower limb spasticity that is disproportionate to weakness, although it differs from lathyrism because of its progressive course and upper limb hyper-reflexia. ${ }^{28}$ In four patients with hereditary spastic paraplegia, CMCT-ADM was normal in three but CMCT-TA was abnormal in all. ${ }^{29}$ In a larger study comprising 25 patients with hereditary spastic paraplegia, MEP was unrecordable from the tibialis anterior in $33 \%$ and, when recordable, was delayed in $75 \%$. The response in the upper limbs was normal in all but five, in whom it was considerably delayed. A lower sensitivity of central motor conduction in the upper limbs was attributed to possible sprouting of pyramidal tract neurons sufficient to normalise central motor conduction even in the presence of upper limb hyper-reflexia. ${ }^{30}$ The neurological state of most of our patients did not alter for many years; regeneration or axonal sprouting may influence the results of both central and peripheral conduction studies. Lack of significant weakness but pronounced spasticity in hereditary spastic paraplegia with marginally prolonged central motor conduction has been attributed to the fact that the generation of spasticity may be a function of small diameter corticospinal fibres. If these were affected it would lead to spasticity without significant weakness and it would not affect the CMCT value either. ${ }^{16}$ The clinical and neurophysiological changes in many of our patients were similar to hereditary spastic paraplegia.

Signs of peripheral neuropathy were not present in any of our patients although one patient had sensory symptoms. Marginal slowing of peroneal nerve conduction and prolongation of MEP latency on cervical and lumbar stimulation suggested subtle and subclinical peripheral nerve involvement in our patients. Peripheral neuropathy in lathyrism is rare and has only been reported in severely affected patients. ${ }^{31}$ Nerve pathology has been reported in two studies only; in one there was honeycombing of peripheral nerves with connective tissue proliferation and in the other thickening and degeneration of myelin..$^{92}$ In a study on 200 patients from Israel with lathyrism peripheral neuropathy was present in $7 \%$ (four) but in a recent study from Bangladesh four of the 16 patients had mild sensorimotor neuropathy, the nerve conduction velocity was marginally slowed, and on EMG, denervation was present in the distal muscles. ${ }^{10}$ High frequency of peripheral neuropathy may account, at least partly, for the SEP abnormalities in three of the 13 patients with lathyrism from Bangladesh. Those abnormalities included absence of a cortical response in two and delay in one. ${ }^{10}$ In our study the SEPs were normal, which is consis- tent with the report of normal posterior columns in the necropsy reports ${ }^{25}{ }^{33}$ although the neuroaxonal degeneration of Goll's tracts has been reported in four of the six necropsy reports on lathyrism..$^{523234}$ The significance of these changes has been questioned because mild pallor and neuronal swelling of Goll's nuclei are common changes in normal aging. ${ }^{5}$ In our study normal tibial SEP and normal sural nerve conduction studies highlight the sparing of the sensory system in lathyrism.

Some of our patients improved to a variable degree in the early period of illness. The conduction in the motor pathways was expected to have an inverse relation with the duration of lathyrism if the conduction time improved with the passage of time but this relation was not significant in our patients $(r=0 \cdot 16)$. Variation in the extent of damage to the motor pathways, predominant involvement of large or small diameter fibres, and the extent of regeneration may obscure the possible relation between central motor conduction and the duration of illness.

To study the neurophysiological changes in lathyrism the effect of oral $L$ sativus and aminodipropionitrile in monkeys has been investigated. Monkeys fed on $L$ sativus developed clinicophysiological evidence of a corticospinal defect after three to 10 months. As in humans, the slowing of central motor conduction was more pronounced in the fibres to the lower limbs. The animals given aminodipropionitrile on the other hand showed clinical and electrophysiological changes not only in central motor pathways but also in the peripheral nerves, central sensory pathways, and cerebellum. ${ }^{8}$ The extrapolation of the results of animal experiments to human beings is not always possible especially in lathyrism because of obvious clinical and electrophysiological differences.

In conclusion our results suggest that in lathyrism central motor conduction is affected in the inferior extremities. Slowing of motor conduction, is considerable in some patients, which suggests the involvement of large diameter corticospinal pathways. On the other hand, marginal slowing or even normal conduction in most patients in the presence of pronounced spasticity and mild weakness suggests the involvement of small diameter corticospinal fibres.

We express our gratitude to $\mathrm{Dr} \mathrm{P} M$ Rossini of Second University, Rome, Italy for his helpful comments. The assistance of Dr C M Pandey, Associate Profest the analysis of data, Mr K S Bisht, and Mr B D Sharma fo electrophysiological tests, $M$ r Anil Kumar for preparation of the manuscript is also gratefully acknowledged.

1 Misra UK, Sharma VP, Singh VP. Clinical aspects of neurolathyrism in Unnao, India. Paraplegia 1993;31: 249-54.

2 Calne DB, McGeer E, Eisen A, Spencer P. Alzheimer's disease, Parkinson's disease and motor neuron disease: Abiotrophic interaction between ageing and environAbiotrophic interaction betwe

3 Spencer P. Guam ALS/Parkinsonism, 'dementia'. A long latency neurotoxic disorder caused by slow toxin(s) in latency neurotoxic disorder caused by

4 Cohn DF, Striefler M. Human neurolathyrism, a followup ohn DF, Striefler M. Human neurolathyrism, a followup
study of 200 patients. Arch Suisses Neurol Neurochir study of 200 patients. Arch
Psychiatrie 1981;128:151-6.

5 Striefler M, Cohn DF, Hirano A, Schujman E. The Central nervous system in a case of lathyrism. Neurology 1977;27:1176-8. 
6 Dastur DK. Lathyrism: Some aspects of disease in man and animals. World Neurol 1962;3:721-30.

7 Rao SLN, Sarma PS, Mani KS, Rao TRR, Sriramachari S. Experiment

8 Hugon J, Ludolph A, Roy DN, Schaumburg HH, Spencer PS. Studies on the etiology and pathogenesis of motor PS. Studies on the etiology and pathogenesis of motor neuron disease II. Clinical and electrophysiological features of pyramidal dysfunction in macaques fed
sativus and IDPN. Neurology 1988;38:435-42.

9 Cohn DF, Streifler M, Dabush S, Messer G. Peripheral nerve changes in chronic neurolathyrism. Neurology India 1983;31:45-5

10 Hugon J, Ludolph AC, Gimenez-Roldon S, Haque A, Spencer PS. Electrophysiological evaluation of human lathyrism-Results in Bangladesh and Spain. In: $A L S$ new advances in toxicology and epidemiology. London: Smith Gordon, 1990:49-56.

11 Prasad LS, Sharan RK. Lathyrism In: Vinken PJ, Bruyn GW, eds. Handbook of clinical neurology. Amsterdam: North Holland Publishing Co, 1969:505-15.

12 Penn RD, Savoy SM, Corcos D, et al. Intrathecal baclofen for severe spinal spasticity. $N$ Engl $\mathcal{F}$ Med 1989;320: for sever

$13 \mathrm{Ma} \mathrm{DM}$, Levison JA. Nerve conduction handbook. Philadelphia: FA Davies, 1983.

14 Katifi HA, Sedgwick EM. Somatosensory evoked potential from posterior tibial nerve and lumbosacral dermatome. from posterior tibial nerve and lumbosa

15 Rossini PM, Caramia MD. Methodological and physiological considerations on electric or magnetic transcranial stimulation. In: Non invasive stimulations of brain and spinal cord: fundamentals and clinical applications, New York: Alan R Liss, 1988:36-65.

16 Thompson PD, Day BL, Rothwell JC, et al. The interpretation of electromyographic responses to electrical stimulation of the motor cortex in diseases of upper motor neurone. $¥$ Neurol Sci 1987;80:91-110.

17 Bernhard CG, Bohm E. Cortical representation and functional significance of the corticomotoneuronal system. Arch Neurol Neurosurg Psychiatry 1954;72:473-502.

18 Takahashi K. Slow and fast group of pyramidal cells and their respective membrane properties. $\boldsymbol{F}$ Neurophysiol their respective

19 Hess CW, Mills KR, Murray NMF, Schriefer TN. Magnetic brain stimulation: central motor conduction studies in multiple sclerosis. Ann Neurol 1987;22: 744-52.
20 Ingram DA, Thampson AJ, Swash $M$. Central motor conduction in multiple sclerosis: evaluation of abnormalitie revealed by transcutaneous magnetic stimulation of brain. F Neurol Neurosurg Psychiatry 1988:51:487-94

21 Kamp WV, Noordhout MD, Thompson PD, Rothwell JC, Day BL, Marsden CD. Correlation of phasic muscle strength and corticomotoneuron conduction time in multiple sclerosis. Ann Neurol 1991;29:6-12.

22 Cheeny PD, Fetz EE. Functional classes of primate corticomotoneuronal cells and their relation to active corticomotoneuronal cells and their

23 Nathan PW, Smith MC. Long descending tracts in man Brain 1940;78:248-303.

24 Puig JS, De Vinals RR. Aportaction a la anatomia patholigica del Latirismo. Rev Clin Esp 1943;8:107-10.

25 Sachdev S, Sachdev JC, Puri D. Morphological study in case of lathyrism. F Indian Med Assoc 1969;52:320-2

26 Thompson PD, Rothwell JC. Day BL, Marsden CD. Clinical applications of central motor conduction studies in man. Noninvasive stimulation of brain and spinal cord. Fundamental and clinical aspects, New York: Alan R Liss, 1985:169-91.

27 Ingram DA, Swash $M$. Central motor conduction is abnormal in motor neuron disease. $\mathcal{f}$ Neurol Neurosurg Psychiatry 1987;50:159-66.

28 Harding AE. Hereditary "Pure" spastic paraplegia: a clinical and genetic study of 32 families. $尹$ Neurol Neurosurg Psychiatry 1981;44:871-83.

29 Claus D, Waddy HM, Harding AE, Murray MNF, Thomas PK. Hereditary motor and sensory neuThomas PK. Hereditary motor and sensory neuropathies and hereditary spastic paraplegia:

30 Schady W, Dick JPR Sheard A. Crompton S. Centra motor conduction studies in hereditary spastic paraplegia. $\mathcal{F}$ Neurol Neurosurg Psychiatry 1991;54:775-9.

31 Mertens HG. Zur Klinik des lathyrismus. Nervenarz 1947;18:493-9.

32 Buzzard EF, Greenfield JG. Pathology of the nervous system. London: Constable Publishing Co, 1921, quoted by Striefler M, Cohn DF, Hirano A, Schujman E. Central nervous system in a case of lathyrism. Neurology 1977;27:1176-8.

33 Ganpathy KT, Dwivedi MP. Studies on clinical epidemiology of lathyrism. Rewa: Indian Council of Medical Research, of lathyri

34 Filimonoff LN. Zur Pathologisch Anatomischen Charakteristik des lathyrismus. Z Ges Neurol Psychiatrie 926;105:76-92. 